\title{
PARTIAL DISCHARGES AND IEC STANDARDS 60840 AND 62067: SIMULATION SUPPORT TO ENCOURAGE CHANGES
}

\author{
Mirza Batalović, Kemo Sokolija, Mesud Haď̌ialić, Nejra Batalović
}

Preliminary notes

This paper addresses some shortcomings of existing IEC standards related to analyses of cable systems with polymer insulation (IEC 60840 and IEC 62067). The focus is on partial discharges measurement, completely neglected in present version of these standards, and justification of the needs for their inclusion in the standards through appropriate procedures. If included in the standards the procedures would provide an effective way to identify and detect the defects that might appear during the cable system installation and to forestall their appearance during exploitation. The simulation evidences, to suggest and justify the changes in the standards, through a modelling of partial discharge phenomena using contemporary software tool (COMSOL) are provided in this paper.

Keywords: COMSOL model; IEC standards; partial discharges

Parcijalna pražnjenja i IEC standardi 60840 i 62067 : Simulacijska podrška za poticanje promjena

Prethodno priopćenje

Ovaj rad upućuje na izvjesne nedostatke postojećih IEC standarda koji se odnose na analizu kabelskih sistema s polimernom izolacijom (IEC 60840 i IEC 62067). Fokus je na mjerenju parcijalnih pražnjenja, potpuno zanemarenih u aktualnoj verziji ovih standarda,te opravdanosti potreba za njihovo uključenje u standarde kroz odgovarajuće procedure. Ukoliko bi se uključile u standarde, procedure bi osigurale učinkovit alat za identifikaciju i detekciju defekata koji se mogu pojaviti za vrijeme instalacije kabelskih sistema i spriječiti njihovu pojavu tijekom eksploatacije. U ovom radu dani su simulacijski dokazi, s ciljem prijedloga za promjene i njihove opravdanosti u standardima, kroz modeliranje fenomena parcijalnih pražnjenja suvremenim programskim alatom (COMSOL).

Ključne riječi: COMSOL model; IEC standardi; parcijalna pražnjenja

\section{Introduction}

According to the fact that population growth in urban areas is in direct and consequent association with growth of energy consumption, power cables are nowadays being used even more frequently. One of the additional reasons for the growth of the implementation of power cables lays in the fact that large number of existing cable network has almost reached the end of its life cycle and for that reason it must be replaced with new ones.

Because of the fact that cables with extruded polymer insulation are easy to install and exploit, also possessing high level of reliability [1], they could provide service for all current loads, starting from low voltage up to the highest transport voltages.

Owing to the development of new insulating materials and their manufacturing technology, properly designed and manufactured with high level of quality control, these cables should have an expected life cycle more than forty years.

With proper selection, consumers have the opportunity to obtain greater reliability [1] and lower life cycle costs for medium and high voltage cables with regard to conventional technologies $[2 \div 5]$. After they have passed the procedure of typical and routine tests in factory, delivered cables are considered to be "healthy", free from any kind of defects.

However, in order to find out if there are any defects present in cable systems, as a result from damages generated during transport, storing and installing, or damages that result from imperfection of an on-site cable accessories assembling process, corresponding tests are being performed on a cable systems after their installation.
Due to the fact that the polymer cable insulation is very sensitive on partial discharge (PD) activities, measuring of $\mathrm{PD}$ represents one of very important procedures in these analyses $[6 \div 11]$. As a matter of fact, the presence of the defect in cable accessories leads to field enhancement inside the defect, and possibility of ignition of PD process. These discharges could cause insulation degradation and lead to cable insulation breakdown.

According to that fact, detection of PD presence could be used as the defect presence indicator and their intensity as level of risk indicator of failure genesis in cable system caused by that presence. Measuring of PD has proven as an effective method for identification and detection of defects in high voltage cable systems with polymer insulation.

In current standards, that regard to analyses of cable systems with polymer insulation (IEC 60840 and IEC 62067), measuring of partial discharges is not mentioned at all, even though it is recommended by appropriate IEEE and CIGRE documents [12,13].

The research proposed inside the frames of this work through a modelling of PD phenomena inside a cylindrical shaped cavity defect, using contemporary software support, has the main goal to confirm justifiability of extending of current IEC standards, in such a manner that they will include procedures for measuring of partial discharges.

In that way effective tool for identification and detection of defects, which result from installation of cable systems would be provided, and the failures that would appear during their exploitation would be forestalled. 


\section{Partial discharges in general}

Partial discharges (PD) represent tiny little arcs that, as their name states, only partially bridge small portion of electrical insulation between phase conductor and ground, or between two phase conductors and which can or cannot occur adjacent to a conductor. They could appear in any point of insulation system where electrical stress, by exceeding the dielectric strength of surrounding media, causes ionization. When speaking of surrounding media, we think of air or other gas that fills the cavities or voids present in solid dielectrics (polymers, ceramics, paper,...), or air bubbles present in liquid dielectrics (insulating oil for example). Besides inside of insulation, partial discharges could appear on the surface of solid dielectrics (surface partial discharges), for instance when that surface is covered with layer of moisturized foreign particles.

Finally, partial discharges are also those generated in gaseous insulation surrounding the protrusions presented on electrodes, and in that case we also call them corona discharges. It is clear from the basic nature of partial discharges that they consequently transmit energy in various forms: electromagnetic radiation (radio waves, light and heat), acoustic radiation (in audio and ultrasonic band) and chemical reactions (forming of ozone and nitrogen oxides). Each of these consequences could be used for detection of presence and measurement of partial discharges intensity.

According to the fact that they do not bridge immediately complete distance between the electrodes, short term partial discharges effects are not dangerous. Long-term considering, since we have tiny little arcs that burn inside the insulation system, partial discharges could gradually and irreversibly destroy electrical insulation.

This destruction could continue and progress up to the moment where insulation system is no longer able to withstand the applied voltage i.e. state known as the breakdown of electrical insulation.

\subsection{Partial discharges classification}

From physical point of view self-sustaining electron avalanches may be created only in gases. Consequently, discharge in solid and liquid dielectrics may occur only in gaseous inclusions, such as voids or cracks in solid materials as well as gas bubbles in liquids.

Therefore PD phenomena occurring in ambient air, such as glow streamer and leader discharges, may also happen in gaseous inclusions. The pulse charge created by glow discharges, often referred to as Townsend discharges is usually in order of few pC. Streamer discharges create pulse charges between about $10 \mathrm{pC}$ and some $100 \mathrm{pC}$. A transition from streamer to leader discharges may occur if the pulse charge exceeds few 1000 pC. Partial discharges are ignited generally if the electrical field strength inside the gaseous inclusions exceeds the intrinsic field strength of the gas. In technical insulation PD events are the consequence of local field enhancement due to imperfections. Therefore partial discharges are defined in IEC 60270 [14] as: Localized electrical discharges that only partially bridge the insulation between conductors and which can or cannot occur adjacent to a conductor. Partial discharges are in general a consequence of local electrical stress concentration in the insulation or in the surface of insulation. Generally, such discharges appear as pulses having duration of much less than $1 \mu \mathrm{s}$. From a technical point of view the following two major kinds of discharges can be distinguished:

\subsubsection{External partial discharges}

Partial discharges in ambient air are generally classified as "external discharges" often referred to as "corona-discharges". Close to the inception voltage first glow and streamer discharge may appear (Fig. 1a). Stable leader discharges may only occur in very long air gaps the meter-range.

Although chemical processes are excited by gas discharges, the created by-products are continuously substituted by the circulating gas. Therefore discharge processes in pure ambient air can be considered as reversible and thus as harmless in general. External discharges in ambient air propagating along solid dielectric surfaces however may become harmful because they may create irreversible degradation processes.

Due to normal and tangential field vectors, leader-like discharges can be ignited often referred as "Toepler discharges" or "gliding discharges". Such discharge type may bridge very long gap distances, even if the test voltage level is raised only few $\mathrm{kV}$ above the leader inception voltage.

Additionally, the solid insulation surface may be eroded progressively due to the local high temperature in propagating leader channels.

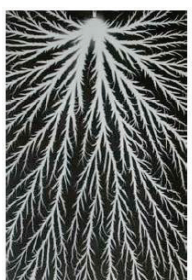

a) Streamer discharge in air [15]

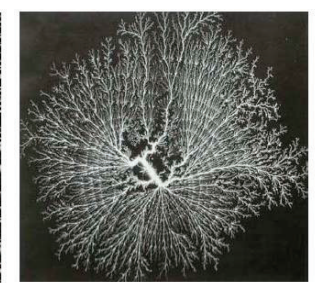

b) Leader discharge in oil [16]

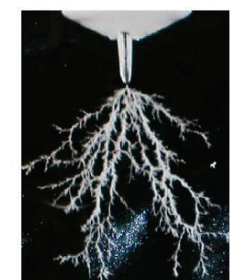

c) Treeing in PMMA [17]
Figure 1 Photographs of typical PD channels

Considering technical insulation systems reversible external discharges in air are representative, for instance, for grading rings of insulators used for HV transmission lines as well as for screening electrodes used for HV test facilities. Irreversible gliding dischages may be ignited on transformer bushings and on power cable terminations due to local imperfections of the field grading.

\subsubsection{Internal partial discharges}

Partial discharge due to imperfection of insulating liquids and solid dielectrics as well as compressed gas are classified as internal discharges. As mentioned previously, self-sustaining electron avalanches are only created in gaseous inclusions. Thus discharges in solid insulations may only be ignited in gas-filled cavities, such as voids and cracks and even in defects of the molecular 
structure. In liquid insulation partial discharges may appear in gas-bubbles due to thermal and electrical phenomena in water-vapour which may be created in high field regions. In principle it is almost impossible to create insulation free from any kind of defects. For solid insulation these defects are given in Fig. 2 below.
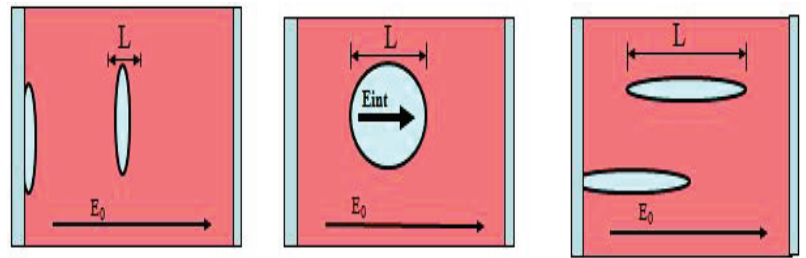

Figure 2 Different forms of defects in solid insulation in which partial discharges might appear

For spherical cavity: $E_{\mathrm{int}}=E_{0} \cdot\left(\frac{3 \varepsilon_{\mathrm{r}}}{2 \varepsilon_{\mathrm{r}}+1}\right)$.

For long thin cylindrical cavity parallel to electric field lines:

$$
E_{\text {int }}=E_{0} .
$$

For wide flat cavity perpendicular to electric field lines:

$E_{\text {int }}=\varepsilon_{\mathrm{r}} E_{0}$.

\section{Generally}

$E_{\text {int }}=f \cdot E_{0}, f \geq 1$.

Because of the fact that electrical stress inside the defect is greater than or equal to the stress in surrounding media, and defect itself is filled with material (gas) with lower dielectric strength than the solid insulation, this stress could lead up to breakdown inside defect if its amount is above the minimum of Paschen's curve ( 3 $\mathrm{kV} / \mathrm{mm}$ for air on normal temperature and atmospheric pressure). Usually, operating stresses inside the insulation of high voltage equipment together with enhancement field factor $f$ exceed the minimum of Paschen's curve, and in dependence on dimensions of defect and pressure in the defect, breakdown of gas could appear inside the defect. When connected to AC sinusoidal voltage, such partial discharge will appear at least once during semi period, and it will cause gradual destruction of surrounding electrical insulation. This destruction could manifest itself in three directions:

- Bombardment of surrounding insulation with ions and electrons;

- Chemical reactions in surrounding insulation, especially at organic insulating materials;

- Radiation from charges-ultraviolet radiation possesses the energy strong enough to cause burst of chains in organic insulation.

In Fig. 3 process of ignition and further development of internal partial discharges is given, and Fig. 4 presents details of electrical treeing process, i.e. resulting with channels that are developing in form of the tree top (Fig.1c).

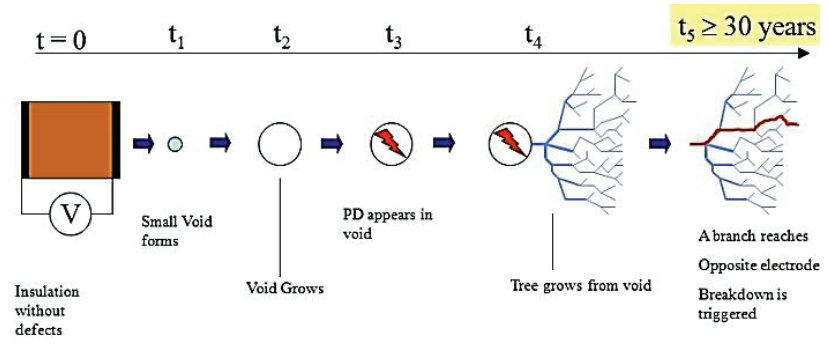

Figure 3 Schematic view of breakdown process caused by partial discharges [18]

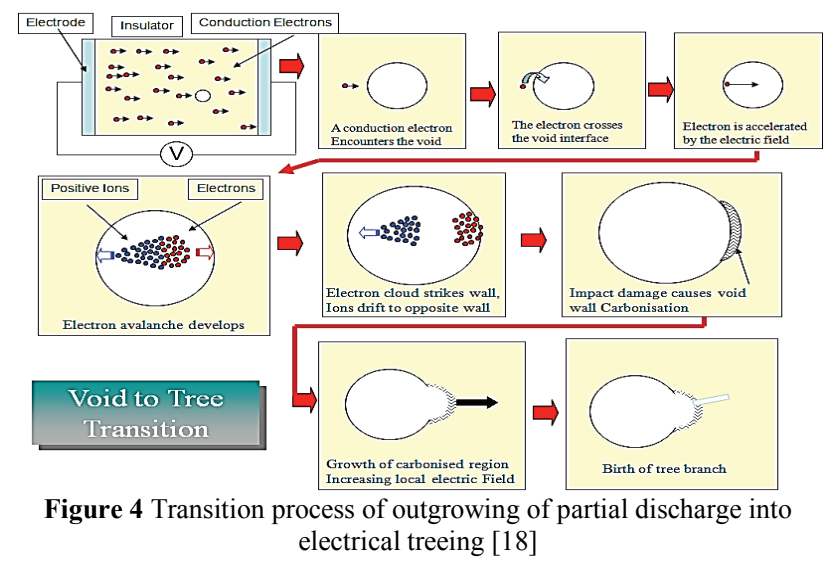

Typical examples of these discharges are the ones that occur inside of polymer insulation of power cablesFig. 5.

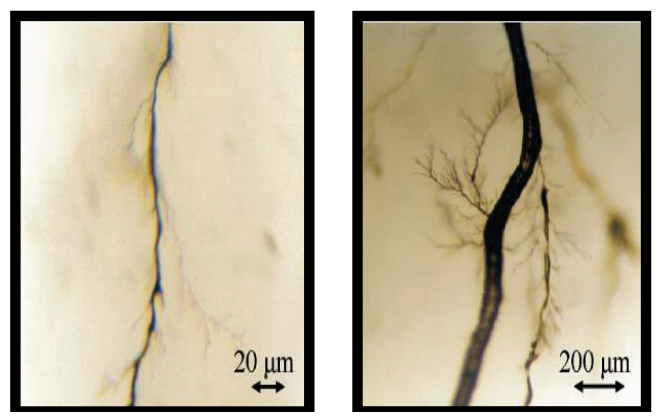

Figure 5 Examples of electrical treeing generated on the tips of wate treeing in XLPE cable insulation [18]

In this way formed channels could grow through insulation very fast or very slow, so that final insulation breakdown could happen after just a few seconds or few years in exploitation. Internal partial discharges are also likely to happen on the interface of solid and liquid insulation and could be harmful in case of "gliding" discharges over the solid insulation surface (Fig. 6).
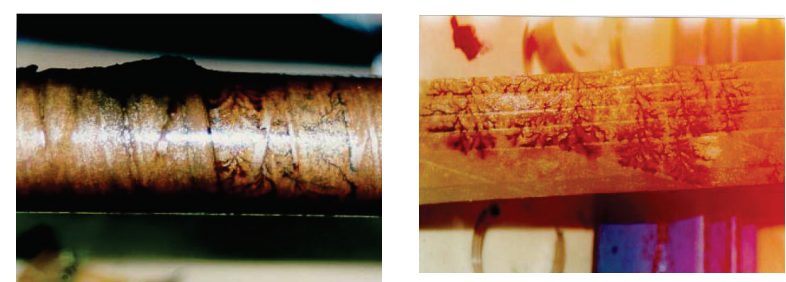

Figure 6 Examples of electrical treeing in cable insulation with oil impregnated paper [19] 
Very harmful are also the internal discharges that occur in gas insulated systems (GIS). These discharges are usually ignited from static or dynamic foreign particles, leading to SF6 gas decomposition and creating of by-products that could destroy solid insulating materials.

\section{Simulation model}

With a goal for illustrating the situation inside the cavity shaped defect, present in insulating material, cylindrical cavity simulation model has been made. The variations in the electric potential magnitude inside the cavity are linked with the surface area of the void as shown in Fig. 7 [20]. Without the inclusion of any stochastic factors, this statement holds true for any type of void, only excluding void with metal wall surfaces [21].

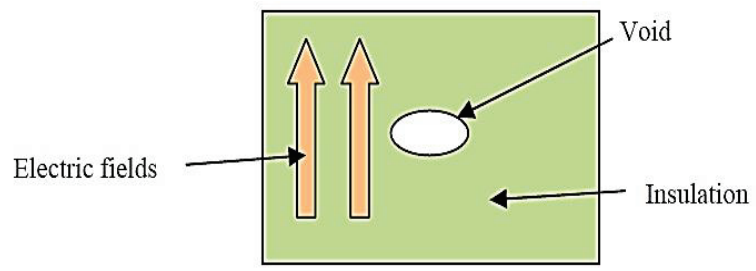

Figure 7 Basic illustration of a disc-void

Partial discharges will occur if and only if the insulation systems satisfy two necessary conditions:

- There must be free electrons available at the surfaces of the void to start an electron avalanche;

- The electric field must be high enough, corresponding to the associated voltage called the Inception Voltage, $U_{\text {inc }}$. The period between $U_{\text {inc }}$ and the starting point of the electron avalanche due to the delay in getting free electrons is called Statistical Time Lag, $\tau_{\text {stat }}$. As a matter of fact, there are two variations for this time delay: Inception delay, which is the time between $U_{\text {inc }}$ and the first discharge, and the second $\tau_{\text {stat }}$ is the time between $U_{\text {inc }}$ and the discharge occurrence, only when previous discharges have occurred [22].

However, only the second $\tau_{\text {stat }}$ is reflected in the PRPDA pattern (practical experiment) if it is longer than several percents of the applied voltage; the inception delay can be seen using other technique such as the PulseSequence Analysis [23]. The discharges will then continue until the electric field in the cavity becomes too low such that it reaches a specific voltage called the Extinction Voltage, $U_{\text {ext }}$ (or Residual Voltage by some authors [20]).

In this work, the $\tau_{\text {stat }}$ value is based on a practical experiment done in the lab by Cecilia Forssén [24] and it has been measured to be $1 \mathrm{~ms}$ on average. However, the users will have the freedom to use a different value of $\tau_{\text {stat }}$ should they want to and this is made available at the start of the simulation in the interactive menu interface. If $\tau_{\text {stat }}$ is negligible to the period of the applied voltage, $T_{\mathrm{v}}$, it will not be included in the simulation to speed up processing.

Up until now however, there is no clear distinction between significant and negligible $\tau_{\text {stat }}$ value and this imposes problems when modelling PD activity.
Therefore, a new method has been introduced inside this paper, to determine the borderline between significant and negligible value for $\mathrm{PD}$ analysis established by $\mathrm{F}$. Baharaudin [25] as below:

$$
\frac{\tau_{\mathrm{v}}}{\tau_{\text {stat }}}<10000 \text { Negligible }
$$

$$
\frac{\tau_{\mathrm{v}}}{\tau_{\text {stat }}} \geq 10000 \text { Significant }
$$

\subsection{Frequency dependent nature of partial discharges}

There are also two time constants that affect and influence the PD activity:

- Charge redistribution time on the cavity surface, $\tau_{\text {cavity }}$. Determined from the conductivity of the cavity surface, $\sigma_{\text {surf }}$, and the geometry of the void; e.g. a higher $\sigma_{\text {surf }}$ and/or a smaller void will result in a shorter $\tau_{\text {cavity }}$.

- The charge redistribution time in the surrounding insulation material, $\tau_{\text {material }}$. Determined from the conductivity and permittivity of the bulk (surrounding) insulation material as well as its geometry; e.g. an increase in conductivity and/or a decrease in permittivity will result in a shorter $\tau_{\text {material }}$. PD activity is dependent on the frequency of applied voltage only when [24]:

$\left\lfloor\tau_{\text {cavity }} \wedge / \vee \tau_{\text {material }}\right\rfloor<T_{\mathrm{v}} \vee: T_{\mathrm{v}}$ $\wedge / \vee\left[\tau_{\text {stat }}\right]>T_{\mathrm{v}} \vee: T_{\mathrm{v}}$.

Both $\tau_{\text {cavity }}$ and $\tau_{\text {material }}$ values can be associated with the 'Screening Effect' and 'Blocking Effect' depending on mutual relationship between them.

For example, a cavity surface that satisfies $\left(\tau_{\text {cavity }}<\tau_{\text {material }}\right)$ condition will prevent any electric field build-ups in the void; decreasing the number of average PD per cycle significantly hence the 'Screening Effect'. This effect should become more profound as the frequency decreases [22]. The 'Blocking Effect' on the other hand occurs when ( $\tau_{\text {cavity }}>\tau_{\text {material }}$ ) whereby the low conductivity value yields a high charge concentration in the cavity surface; increasing the chances for PD to occur.

As a result, the average number of PD per cycle increases [26].The frequency dependent PD activity can also be associated with the dispersion effect in the permittivity. The dielectric material will have an enhancement factor to be considered [27]. Its relative permittivity varies with the frequency of the applied voltage and these yields to one of the sources for the frequency dependent nature of $U_{\text {inc }}$ [22]. In this project however, the model was simulated to be non-dispersive.

\subsection{Simulation model specifications}

In order to verify the results of partial discharge simulation process in this work, the same sample that has been previously tested in laboratory is modelled, Fig. 8 [21]. Figure 8 above represents the real structure of the simulated disc-void PD analysis using epoxy resin covering the whole part of the polycarbonate plates to 
prevent any discharges at the electrode's edge due to the high electric fields applied. Three polycarbonate plates each of $1 \mathrm{~mm}$ thick and $14 \mathrm{~mm}$ in diameter are placed on top of each other with the middle plate being drilled at the centre to resemble a void with $10 \mathrm{~mm}$ of diameter. A 10 $\mathrm{kV}$ sinusoidal voltage is then applied between the electrodes with its frequency ranges from $0,01 \mathrm{~Hz}$ to 100 $\mathrm{Hz}$.

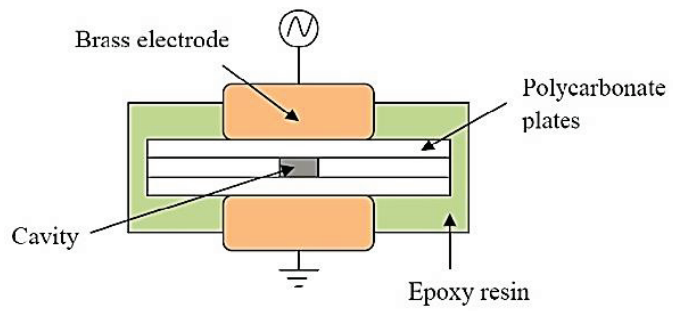

Figure 8 Brass electrode Polycarbonate plates Epoxy resin Cavity

The basic governing equations are as below [24]:

$\operatorname{div} \vec{D}=\rho$

$\operatorname{div} \vec{J}+\frac{\partial \rho}{\partial t}=0$

with $\vec{D}$ as the electric displacement field, $\rho$ as the free charge density, and $\vec{J}$ as the free current density. But for non-dispersive, linear isotropic dielectrics exposed to slowly varying fields, Eqs. (8) and (9) can be combined as follows:

Eq. (8) could be written as:

$-\varepsilon \operatorname{div}(\operatorname{grad} V)=\rho$

Differentiating (10) in time we have:

$\frac{\partial \rho}{\partial t}=-\varepsilon \operatorname{div}\left[\operatorname{grad}\left(\frac{\partial V}{\partial t}\right)\right]$.

Equation (9) then could be written as:

$-\sigma \operatorname{div}(\operatorname{grad} V)+\frac{\partial \rho}{\partial t}=0$

Combining last two equations we will get:

$\operatorname{div}\left[-\sigma \operatorname{grad} V-\varepsilon \operatorname{grad}\left(\frac{\partial V}{\partial t}\right)\right]=0$.

or using operator notation

$$
\nabla\left[-\sigma \nabla V-\varepsilon \nabla\left(\frac{\partial V}{\partial t}\right)\right]=0,
$$

where $\sigma$ equals the electric conductivity, $V$ equals the applied electric potential and $\varepsilon$ the permittivity [24].

$\mathrm{PD}$ activity in the cavity was modelled as an increase in the associated channel conductivity value and they were modelled to behave as Eq. (15) below; where $\sigma_{0}$ is the initial channel's electrical conductivity value before discharging, $I$ is the current across the channel, $U$ is the electric potential difference across the channel and $I_{\text {crit }}$ is the critical current value to start an electron avalanche [24].

For numerical reasons the conductivity needs to be limited to a maximum value of $\sigma_{\max }$ (i.e. $1 \times 10^{-4}$ ) in order to achieve numerical convergence for the final solution and calculation.

$\sigma= \begin{cases}\sigma_{0} \mathrm{e}^{\left(\left|\frac{U}{U_{\text {inc }}}\right|+\left|\frac{t}{t_{\text {cr }}}\right|\right)} \text { during discharge } \\ \sigma_{0} \quad \text { otherwise. }\end{cases}$

$I= \begin{cases}\iint_{S} J \mathrm{~d} S=-\sigma_{0} \iint_{S} \sigma \nabla V \mathrm{~d} S \text { during discharge, } \\ 0 & \text { otherwise. }\end{cases}$

Eq. (16) above is the equation for the current through the discharging channel [24]. Notice that $I$ and $\sigma$ in both equations above are dependent on each other. The only difference is that they are of a different time step; i.e. $\sigma$ takes the value of $I$ from the previous time step. At the frequency where $\tau_{\text {stat }}$ is significant in comparison to the $T_{\mathrm{v}}$, Eq. (17) below needs to be used in addition to the $U$ inc limit alone to initiate PD [24]:

$P= \begin{cases}\frac{I_{e 00} \mathrm{e}^{\left|\frac{U}{U_{\text {inc }}}\right|}}{N} \mathrm{~d} t, & U>U_{\text {inc }} \\ 0, & U<U_{\text {inc }}\end{cases}$

where $P$ is the probability of $\mathrm{PD}$ occurring, $I_{\mathrm{e}_{0}}$ is the initial electron injection intensity and $N$ is the number of channels inside the cavity. The value of $\mathrm{d} t$ needs to be calculated using Eq. (18).

$\mathrm{d} t=\frac{\text { time stepping interval during PD act. }\left({ }^{\circ}\right)}{360^{\circ} \cdot f}$,

so that $P$ can be compared with a random number $R$ which lies within the range of $0<R<1$ such that [24]:

$P>R$ PD occurs
$P<R$ no

For the case of having more than one channel that exceeds $U_{\text {inc }}$, only one channel will be chosen randomly to discharge by MATLAB.

\subsection{Model designing procedures}

In order to achieve acceptable and confidential simulation results, geometry used in this model is the same as used by previous authors in their works (F. Cecilia [24], F. Baharaudin [25]). 
This was done in order to secure the output integrity and in the same time to verify validity of this model, and to enable its application for different geometry and parameters analyses.

Although 'Multiphysics module' is capable of modelling PD activity, it is too general in simulating applications; introducing unnecessary variables.

As a result, the Quasi-Statics meridional electric currents option was chosen (application mode name: emqvw) in the 'Model Navigator' window; i.e. the Quasistatics of conducting and dielectric materials with small currents in the $(r, z)$-plane, and a negligible coupling between the electric and magnetic fields.

This is preferable because it further simplifies the model by omitting any magnetic field influences; and it is also capable of solving both transient and time-harmonic analysis.

To add some random behaviour of the PD activity, the void was divided into 3 different channels; each having equal volume of space. This was done to illustrate that the discharges may occur at only some parts of the cavity. The calculations are as below: The volume of the cylindrical cavity is

$$
V=\pi \cdot r^{2} \cdot h=\pi \cdot 0,005^{2} \cdot 0,001=78,5 \mathrm{~mm}^{3},
$$

where $r$ is the outer radius of cylinder and $h$ is the height of cylinder. If we now divide the cavity in three channels with equal volume each, then every channel gets 26167 $\mathrm{mm}^{3}$ of total volume. Channels actually represent cylinders with radius $R_{1}, R_{2}$ and $R_{3}$ Fig. 9 .

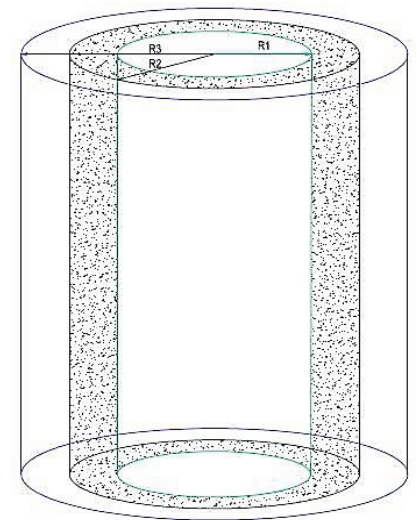

Figure 9 Illustration of channels in cylinder shaped shells

2D axial symmetry view of cavity divided in channels, Fig. 10.

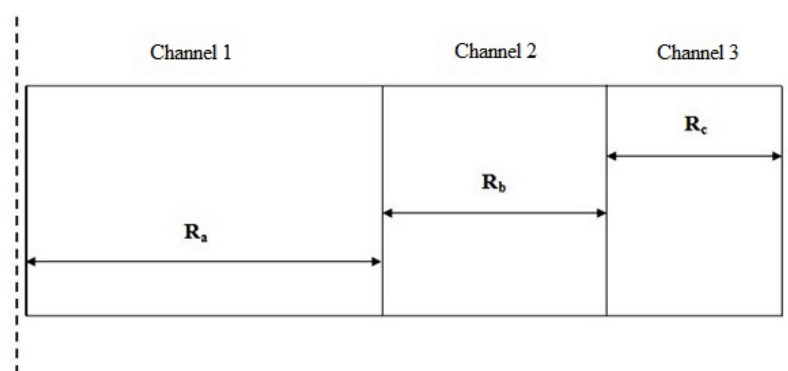

Figure 10 Radius distribution for each channel

\section{Channel 1 (Cylinder $\left.R_{1}\right)$}

$R_{1}=R_{a}, V_{1}=R_{1}^{2} \pi H$

\section{Channel 2 (Cylinder shell)}

$V_{2}=\left(R_{2}^{2}-R_{1}^{2}\right) \pi H$

\section{Channel 3 (Cylinder shell)}

$V_{3}=\left(R_{3}^{2}-R_{2}^{2}\right) \pi H$

From $V=$ const. $\Rightarrow V_{1}=V_{2}$

$\Rightarrow R_{1}{ }^{2} \pi H=\left(R_{2}^{2}-R_{1}^{2}\right) \pi H \Rightarrow R_{1}=\frac{\sqrt{2}}{2} R_{2}$

From $V_{2}=V_{3} \Rightarrow\left(R_{2}{ }^{2}-R_{1}{ }^{2}\right) \pi H=\left(R_{3}{ }^{2}-R_{2}{ }^{2}\right) \pi H$

$\Rightarrow R_{3}=\sqrt{\frac{3}{2}} R_{2}$

When drawing the specified geometry, obtained relations (24) and (25) between the radii must be fulfilled. Cavity surface was added in the model by adding layers of $0,1 \mathrm{~mm}$ thick surrounding the void. The model is as Fig. 11 .

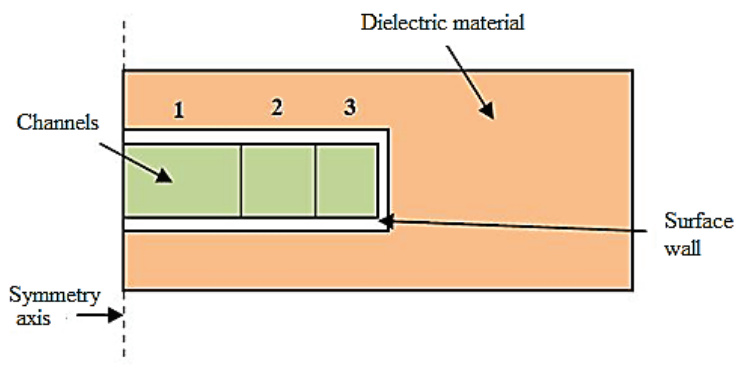

Figure 11 Axial symmetry mode in COMSOL Mph

In simulations that use Finite element method (FEM) it is necessary to divide the domain of interest into finite number of elements, Fig. 12.

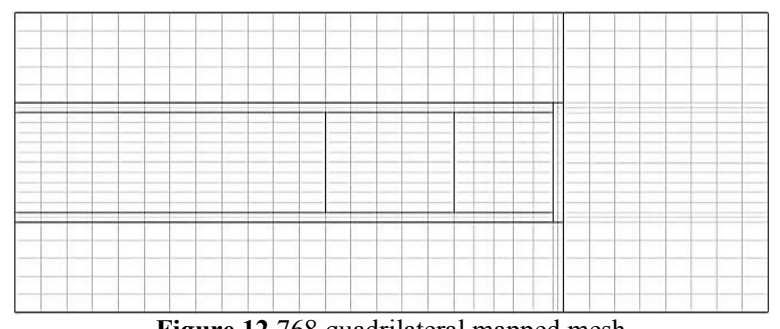

Figure 12768 quadrilateral mapped mesh

This model uses the 'Mapped Mesh' method instead of the default random meshing; ultimately due to the nature of the geometry used and its electric fields which propagate vertically ( $z$-axis).

Hence, precise space allocations were calculated for each sub domain in order to map the mesh evenly. The cavity was given more attention by tightening the distance between the meshing lines, whereas the surrounding insulators were set to the exact opposite. 
This was done to gain optimum data accuracy in the cavity more than the rest of the sub domain hence maximizing the overall simulation speed. As a preventative measure, the points along each boundary were made identical across the sub domain to prevent edge discretisation error (Error 4026).

The Edge Vertex Distribution (EVD) for each boundary line was calculated and defined under the 'Mapped Mesh Parameters' menu which uses vector ratio format in such a way that the number of points along the edges varies between 0 and 1 .

\section{Performed investigation}

The model was simulated using frequencies ranging from $0,01 \mathrm{~Hz}$ to $100 \mathrm{~Hz}$ and the average PD per period cycle over the total of 20 cycles was recorded. Previous investigations show that the ratio between the $U_{\text {inc }}$ and $U_{\text {ext }}$ was found to be around 1,1 to 1,3 [28]. This means that the $U_{\text {ext }}$ used in the simulation should be around $3500 \mathrm{~V}$ to $4200 \mathrm{~V}$ with respect to the $4600 \mathrm{~V}$ of $U_{\text {inc }}$ value.

Therefore, there is a need to investigate this fact in the simulation model to see how high value of $U_{\text {ext }}$ affects the average number of PD per period cycle for various frequencies. Also, the amplitude of the applied voltage was varied from $8 \mathrm{kV}$ to $12 \mathrm{kV}$ in $2 \mathrm{kV}$ steps to see any effects towards the PD activity inside the

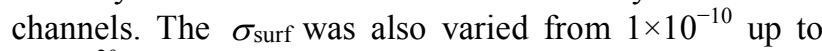
$1 \times 10^{-20} \mathrm{~S} / \mathrm{m}$ to see any variations in the PD activity. Most of the additional investigations were simulated once at the low frequency region and once again at the high frequency. With the help of interactive menu at the start of the simulation, the variables used for the additional investigations can be keyed in easily and quickly.

\subsection{Number of cycles and time stepping interval}

Using a very small time step interval will produce accurate simulation results but at the expense of having a very large data size (198 $\mathrm{MB}$ for the $1^{\circ}$ interval per frequency) and a very long simulation time; conversely is true for using a very large time step.

The first analysis was to determine the optimum time stepping interval required to obtain respectable and accurate results. It can be thought as though MATLAB is actually sampling the real world laboratory experiment; only in this work, it samples out COMSOL simulation data. $1^{\circ}$ of phase interval was used initially and the result for the first $720^{\circ}$ phase angle is as shown in Fig. 13.The simulation is then repeated for the $3^{\circ}$ and $9^{\circ}$ phase interval for 2 complete cycles with the results as shown in the same graph. All of the three simulations ran at 0,01 $\mathrm{Hz}$ of the applied voltage frequency.

$1^{\circ}$ time stepping phase interval was used as a reference because it possesses the highest accuracy in data sampling as compared to $3^{\circ}$ and $9^{\circ}$ interval. Looking at Fig. 14 in around $45^{\circ}$ to $55^{\circ}$ phase angle, PD occurs in all three simulation models; only the $1^{\circ}$ interval model discharges in Channel 2 while the others discharge in Channel 1.

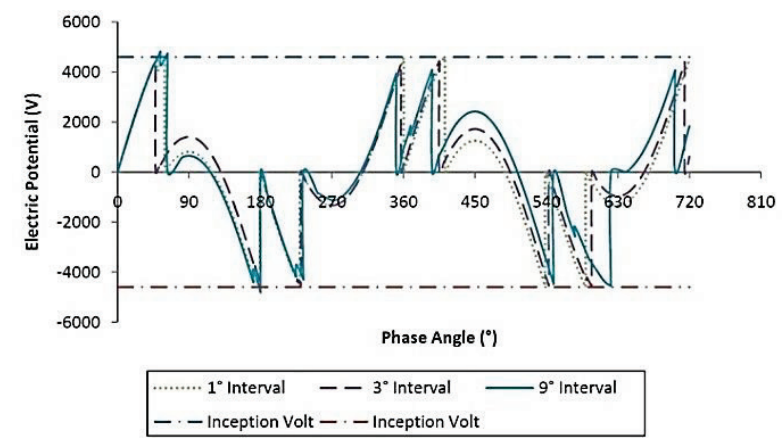

Figure 13 An electric potential across Channel 1 with various time stepping intervals used at $0,01 \mathrm{~Hz}$. The steep, long vertical line represents a sudden drop in electric potential value across Channel 1 due to PD

Ideally, at a very low frequency such as $0,01 \mathrm{~Hz}$, there should be no delay for PD occurrences the moment the electric potential across any channel reaches $U_{\text {inc }}$. However, the $9^{\circ}$ interval graph line discharges incorrectly beyond the $U_{\text {inc }}$ limit. This is largely due to the big gap in data sampling by MATLAB, making it fail to keep up feeding in new conductivity value to all of the channels back to COMSOL; leading MATLAB to produce erratic simulation results.

As a result, the $3^{\circ}$ interval was chosen as the time step interval during no PD activity because it has a close agreement with the $1^{\circ}$ interval data throughout the simulation as well as generating a proper file size with an acceptable simulation processing time.

During any PD activity, the time stepping will change to $0,02^{\circ}$ phase angle until it reaches $U_{\text {ext }}$ where it will exit the PD loop mode, and revert back to use the $3^{\circ}$ interval phase angle. Cecilia Forssén in her thesis used 20 cycles (i.e. $7200^{\circ}$ ) per frequency to run the simulation [26].

However, it is unknown as to whether or not running at lower cycles per frequency will produce the same results and thus save a lot of time; and if so, what values of cycles per frequency will be adequate.

For that reason, investigations were made to observe any effects of lowering the number of cycles per frequency to the number of PD occurrences per cycle.

From the table below, $0,01 \mathrm{~Hz}$ produces a more consistent result throughout the full 20 cycles as compared to the $50 \mathrm{~Hz}$ applied frequency. This is mainly caused by the negligible $\tau_{\text {stat }}$ at any frequency below or equal to $0,1 \mathrm{~Hz}$ i.e. only Eqs. (15) and (16) are used hence less random effect.

Statistically, this is proven to be true where $0,01 \mathrm{~Hz}$ has a lower population variance than the $50 \mathrm{~Hz}$ data; 1,7275 to 2,26 respectively. Clearly, running the simulation at a value less than 20 cycles for the $50 \mathrm{~Hz}$ frequency will give out inaccurate average PD occurrences per cycle due to the large variations throughout the 20 cycles; inhibiting any data comparison integrity. As a result, 20 cycles per frequency were used in all simulations covering various frequencies.

\subsection{Average number of PD per cycle}

The model was simulated under various frequencies of the applied voltage i.e. $0,01 \mathrm{~Hz}, 0,1 \mathrm{~Hz}, 1 \mathrm{~Hz}, 10 \mathrm{~Hz}$, $50 \mathrm{~Hz}$ and $100 \mathrm{~Hz}$. Average time needed for these 
simulations was 6,5 hours. It might be safe to assume generally that the time it takes to simulate the model for each frequency is inversely proportional to the frequency of the applied voltage.

However, it does not necessarily mean that the PD activity will also follow this trend and this is reflected in the $0,01 \mathrm{~Hz}$ data where the duration is in fact shorter than the next higher frequency which is the $0,1 \mathrm{~Hz}$. To explain this further, refer to Fig. 14.

Table 1 Average number of partial discharges for various frequencies of applied voltage [29]

\begin{tabular}{|c|c|c|c|c|c|c|}
\hline & \multicolumn{5}{|c|}{ Number of partial discharges } \\
\hline Phase angle & $0,01 \mathrm{~Hz}$ & $0,1 \mathrm{~Hz}$ & $1 \mathrm{~Hz}$ & $10 \mathrm{~Hz}$ & $50 \mathrm{~Hz}$ & $100 \mathrm{~Hz}$ \\
\hline $0^{\circ} \div 360^{\circ}$ & 8 & 8 & 7 & 4 & 1 & 0 \\
\hline $361^{\circ} \div 720^{\circ}$ & 8 & 8 & 6 & 2 & 2 & 0 \\
\hline $721^{\circ} \div 1080^{\circ}$ & 8 & 8 & 6 & 5 & 3 & 1 \\
\hline $1081^{\circ} \div 1440^{\circ}$ & 8 & 8 & 7 & 5 & 3 & 2 \\
\hline $1441^{\circ} \div 1800^{\circ}$ & 8 & 8 & 6 & 8 & 2 & 2 \\
\hline $1801^{\circ} \div 2160^{\circ}$ & 8 & 8 & 8 & 7 & 3 & 1 \\
\hline $2161^{\circ} \div 2520^{\circ}$ & 8 & 8 & 8 & 5 & 0 & 1 \\
\hline $2521^{\circ} \div 2880^{\circ}$ & 8 & 8 & 8 & 5 & 3 & 1 \\
\hline $2881^{\circ} \div 3240^{\circ}$ & 8 & 8 & 8 & 6 & 2 & 4 \\
\hline $3241^{\circ} \div 3600^{\circ}$ & 8 & 8 & 6 & 4 & 5 & 0 \\
\hline $3601^{\circ} \div 3960^{\circ}$ & 8 & 8 & 6 & 5 & 4 & 2 \\
\hline $3961^{\circ} \div 4320^{\circ}$ & 8 & 8 & 6 & 4 & 3 & 1 \\
\hline $4321^{\circ} \div 4680^{\circ}$ & 8 & 8 & 6 & 6 & 4 & 1 \\
\hline $4681^{\circ} \div 5040^{\circ}$ & 8 & 8 & 8 & 5 & 1 & 2 \\
\hline $5041^{\circ} \div 5400^{\circ}$ & 8 & 8 & 6 & 5 & 0 & 2 \\
\hline $5401^{\circ} \div 5760^{\circ}$ & 8 & 8 & 6 & 6 & 2 & 2 \\
\hline $5761^{\circ} \div 6120^{\circ}$ & 8 & 8 & 7 & 6 & 2 & 0 \\
\hline $6121^{\circ} \div 6480^{\circ}$ & 8 & 8 & 6 & 7 & 3 & 2 \\
\hline $6481^{\circ} \div 6840^{\circ}$ & 8 & 8 & 6 & 6 & 2 & 1 \\
\hline $6841^{\circ} \div 7200^{\circ}$ & 8 & 8 & 6 & 6 & 2 & 3 \\
\hline $\mathbf{A v e r a g e}^{\circ}$ & 8 & 8 & 6,65 & 5,35 & 2,35 & 1,4 \\
\hline
\end{tabular}

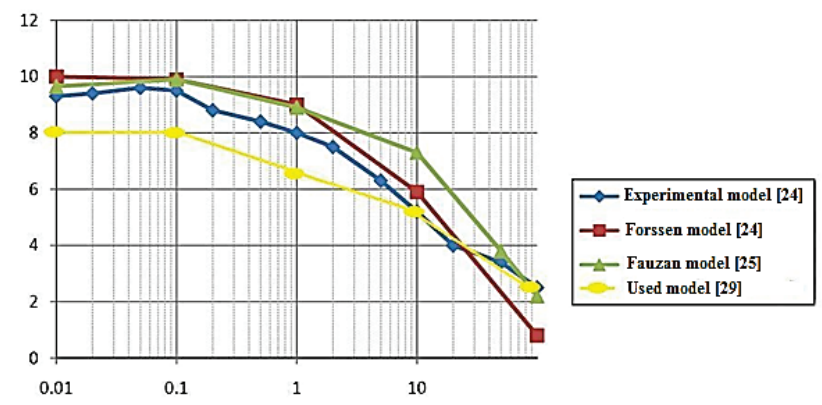

Figure 14 Average PD per cycle for various frequencies, comparing the practical lab experiment, existing previous PD simulation models and model used in this work

At $0,01 \mathrm{~Hz}$, its average PD per cycle is in fact lower than the average PD per cycle of the $0,1 \mathrm{~Hz}$ frequency. This means, the total simulation time per frequency is behaving proportionally to the number of discharges per cycle; and this seems to be logical because for every PD occurrence, MATLAB will switch into the PD activity program loop which uses $0,02^{\circ}$ as the time stepping interval. For example, instead of stepping from $45^{\circ}$ to $48^{\circ}$ (default $3^{\circ}$ interval), MATLAB will sweep in $0,02^{\circ}$ time step from $45^{\circ}$ up to an angle at which the electric potential across the specific discharging channel reaches $U_{\text {ext }}$ (usually after 3 times of $0,02^{\circ}$ time step i.e. $45,06^{\circ}$ ). Only then MATLAB will revert back to the $3^{\circ}$ time steps and repeat the simulation again starting at $48^{\circ}$ phase angle.

In other words, COMSOL will be called at least three times more to account for the additional time stepping interval. At frequencies above $0.1 \mathrm{~Hz}$ (i.e. where the $\tau_{\text {stat }}$ is significant), the program will simulate $\tau_{\text {stat }}$ influence to the PD activity by including Eqs. (17), (18) and (19) in choosing only one to discharge for the next time step. Clearly, the $1 \mathrm{~Hz}$ frequency is affected by the inclusion of those additional equations and hence extra time spent. Although the additional time might not be much, but over 20 cycles, the time delay sums up to cost $1 \mathrm{~Hz}$ frequency additional 30 minutes; longer than $0,01 \mathrm{~Hz}$ even though $0,01 \mathrm{~Hz}$ has more PD. Referring to the trend line of Fig. 14 , it can be seen that close agreements have been reached between the simulated model, Cecilia Forssén's model [24], the actual practical experiment (done by Cecilia Forssén as well [26]) and Fauzan model [25].

This ultimately proves that the simulation model produced and programming code generated for this project are correct and acceptable as a whole to be used for any other PD analysis using different parameter values. It is of great interest to see any electric field variations in the simulation model itself rather than using only graphs.

Here we will display figures stored by COMSOL at the end of each simulation, for two values of frequency: $0,01 \mathrm{~Hz}$ and $50 \mathrm{~Hz}$. From these figures we are able to notice different activities during the process of partial discharges: accumulation of charges right before discharge, higher concentration of electric field lines inside certain channels, discharges in some channels, etc.

In Fig. 15 we can clearly see higher intensity of electric field inside the cavity than its surrounding media. Reason for that is lower value of dielectric permittivity inside the cavity.

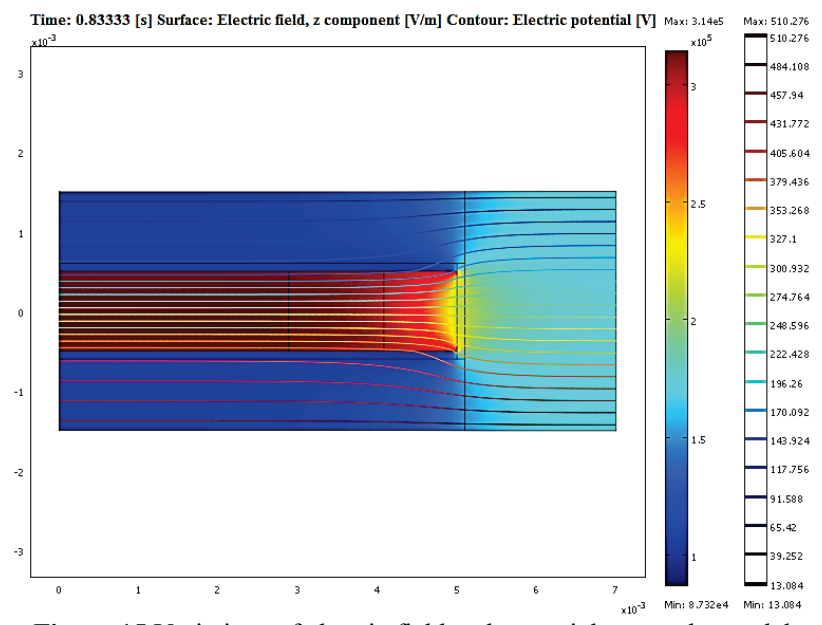

Figure 15 Variations of electric field and potential across the model before discharging at $0,01 \mathrm{~Hz}$

Appearance of stronger electric field intensity is illustrated with red colour and more narrow electric field lines inside the cavity. In Fig. 16 we can notice that PD occurred in Channel 1 approximately at time of around $13,4 \mathrm{~s}$.

Immediately after that (after 3,33 s) second PD occurs in Channel 3, Fig. 17. Note however that the surface colour and contour lines in all figures are not 
identical in magnitude representation even though they are of the same colour. For $50 \mathrm{~Hz}$ we have different situation because we can notice a clear illustration of the $\tau_{\text {stat }}$ effect in the overall PD activity for an identical model simulated at $0,01 \mathrm{~Hz}$ and $50 \mathrm{~Hz}$. That is the reason why we have less PD per cycle.

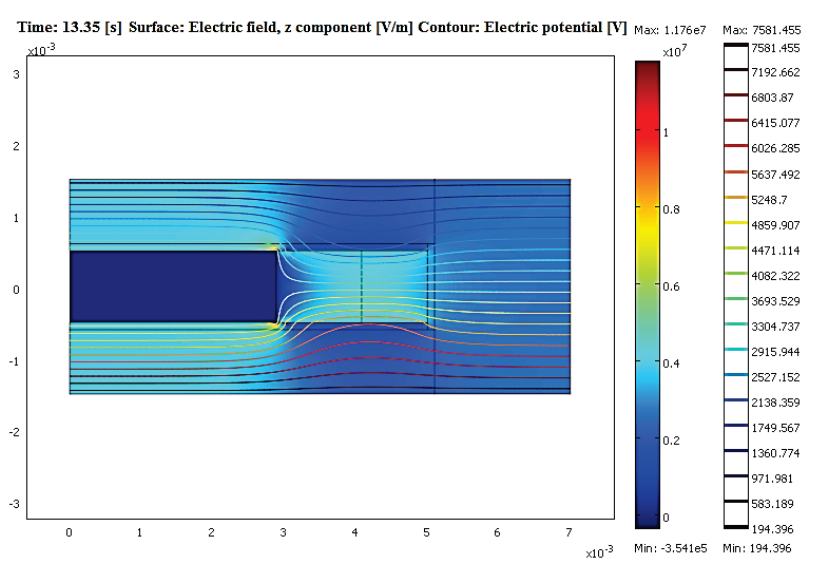

Figure 16 Variations of the electric fields and potentials across the model right after $\mathrm{PD}$ in Channel 1 at $0,01 \mathrm{~Hz}$

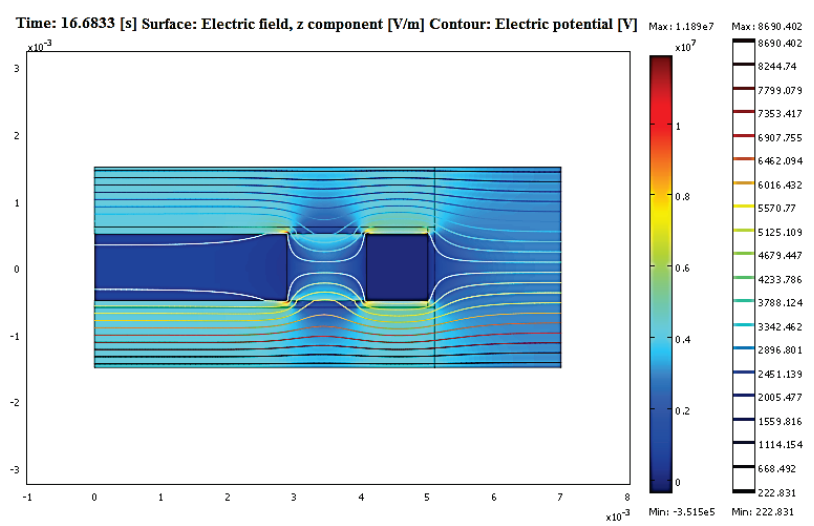

Figure 17 Variations of the electric fields and potentials across the model right after PD in Channel 3 at $0.01 \mathrm{~Hz}$

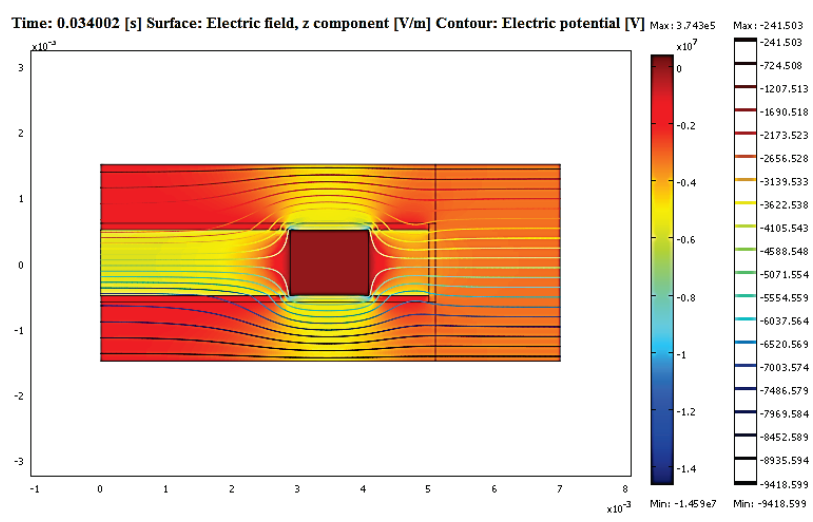

Figure 18 Variations of the electric fields and potentials across the model right after PD in Channel 2 and after maximum value of the applied voltage is reached at $50 \mathrm{~Hz}$

We can observe that effect from Fig. 18 where in two time steps we have only one discharge. In Fig. 18 we can see the influence from discharge in Channel 2 on Channels 1 and 3. That was illustrated by red and yellow colour at the edges of Channel 2. Right after that, discharge follows in channel 3 Fig. 19 because it was clearly more influenced by the discharge in Channel 2, and that confirms the fact that surface colour and contour lines in all figures are not identical in magnitude representation even though they are of the same colour.

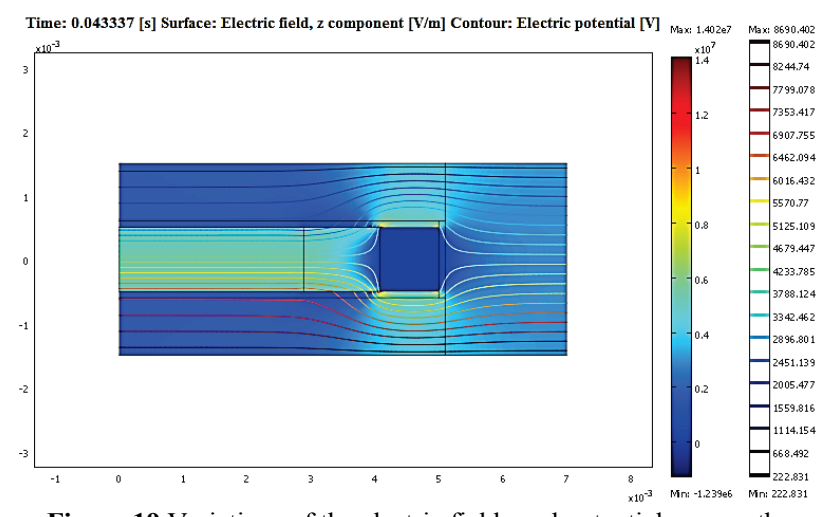

Figure 19 Variations of the electric fields and potentials across the model right after PD in Channel 3 and after drastical decrease of the applied voltage due to previous discharges in other channels at $50 \mathrm{~Hz}$

\section{Conclusion}

Based on the results presented in this work the following conclusions are drawn:

- Using seamlessly interoperability of COMSOL and MATLAB software in this work, simulation of the complex and random nature of PD activity has been performed. The results obtained from simulations for various frequency values confirm the validity of the used model.

- COMSOL also facilitates final data analyses by visual effect, in such a manner that it stores a set of pictures and animation after the end of each simulation.

- Using less degree of freedom (2989 comparing to previous model where its value amounts to 5978) average simulation time was shortened from $6 \div 30$ hours to $10 \div 14$ hours, depending on selected value of frequency.

- Consideration of this phenomenon for various frequency values gives a more profound insight into the essence in order to better understand it.

For all the reasons mentioned above, we may conclude that this model represents convenient platform for simulating PD activity for various types of dielectric material exposed to high electric fields. Main goal of this paper was to encourage the changes inside the current IEC standards (60840 \& 62067) through the simulation model in such a manner that they should include the procedures for PD measurements, by adverting once more on the PD phenomena complexity and significance for high voltage insulation.

\section{References}

[1] Kovač, Z.; Knežević, G.; Topić, D. Modelling of power system reliability assessment. // Technical Gazette. 20, 1(2013), pp. 93-98.

[2] Thue, W. A. Electrical Power Cable Engineering. Marcel Dekker, Inc., 1999.

[3] Bartnikas, R.; Srivastava, K. D. Power and Communication Cables - Theory and Applications. John Wiley \& Sons, 2000 . 
[4] Sokolija, K.; Batalović, M. Contemporary trends in material selection and design of medium voltage with polymer insulation.(in Bosnian: Suvremeni trendovi $u$ izboru materijala i dizajna srednjenaponskih ekstrudiranih kabela). // Josip Lončar days, Proceedings of the $20^{\text {th }}$ International symposium for electrical engineering, Šibenik 2010.

[5] Peschke, E.; Von Olshausen, R. Cable Systems for High and Extra - High Voltage. // Publics MCD Verlag, 1999.

[6] Wester, J. Condition Assessment of Power Cable using Partial Discharge Diagnosis at Damped AC Voltages. // Ph. D. Dissertation, Delft University of Technology, 2004.

[7] Setyawan, J. Investigation of partial Discharge Occurance and Defectability in High Voltage Power Cable Accessories. // MSc Graduation thesis, Delft University of Technology, 2009.

[8] Kruger, F. H. Partial Discharge Detection in High Voltage Equipment. Butterworths \& Co Ltd, London, 1989.

[9] Boggs, S.; Densley, J. Fundamentals of Partial Discharges in the context Field Cable Testing. // IEEE Electrical Insulation Magazine. 16, 5(2000), pp. 13-18. DOl: 10.1109/57.871416

[10] IEC 62067: Standard Power cables with extruded insulation and their accessories for rated voltages above $150 \mathrm{kV}$ (Um $=170 \mathrm{kV})$ up to $500 \mathrm{kV}(\mathrm{Um}=550 \mathrm{kV})$ - Test methods and requirements.

[11] Ladde, R. C. Partial Discharge Diagnosis of High Voltage Power Cable Accessories. // MSc Graduation thesis, Delft University of Technology, Delft, 2007.

[12] IEEE Std 400.3TM-2006: Guide for Partial Discharge Testing of Shielded Power Cable Systems in a Field Environment.

[13] CIGRÉ Technical Brochure No. 182 Partial Discharge Detection in installed HV extruded cable systems. // CIGRÉ WG 21.16, April 2001.

[14] IEC 60270: High-Voltage Test Techniques-Measurement of Partial Discharges by Electromagnetic and Acoustic Methods (third edition).

[15] Lemke, E. Durchschlagspannungs Kennlinien von inhomogenen Luftunkenstrecken bei Schaltspannungen Durchschlagmechanismus und Schlagweite. // Ph.D. Thesis, TU Dresden, 1967.

[16] Hauschild, W. Zum Oldurchschlag in inhomogenen Feld bei Schaltsoannungen. // Ph.D. Thesis, TU Dresden, 1970.

[17] Takanashi, Y. Two hundred Years of Lichtenberg Figures. // Journal of Electrostatics. 6, (1979), pp. 1-13. DOI: 10.1016/0304-3886(79)90020-2

[18] Sokolija, K. Partial discharges. (In Bosnian: Parcijalna pražnjenja). http://c2.etf.unsa.ba/course/view.php?id=28.

[19] Hickes, S. On-Line Partial Discharge Testing, Emerson Process Management. http://www.freepatentsonline.com/ 7183776.html.

[20] Suzuki, H.; Aihara, K.; Okamoto, T. Complex behaviour of a simple partial-discharge model. // Europhysics Lett. 66, 1(2004), pp. 28-34. DOI: 10.1209/epl//2003-10151-x

[21] Wu, K.; Suzuoki, Y.; Dissado, L. A. The contribution of discharge area variation to partial discharge patterns in disc-voids. // J. Phys. D: Appl. Phys. 37, 13(2004), pp. 1815-23. DOI: 10.1088/0022-3727/37/13/013

[22] Hans, E. Partial Discharges Studied with Variable Frequency of the Applied Voltage. // Ph.D. Dissertatio, Kungl Tekniska Högskolan, Stockholm, 2001.

[23] Hoof, M.; Patsch, R. Pulse-Sequence Analysis: a new method for investigating thephysics of PD-induced ageing. // IEE Proc. Sci. Meas. Tech. 142, 1(1995), pp. 95-101.

[24] Hans, E.; Forssen, C. Modeling of a discharging cavity in a dielectric material exposed to high electric fields. // Proceedings of the COMSOL Multiphysics User's Conference / Stockholm, 2005.
[25] Fauzan, B. Modelling Partial Discharges in a Solid Dielectric Material's Cavity using COMSOL ${ }^{\mathrm{TM}}$ and MATLAB ${ }^{\mathrm{TM}}$ Software. // MSc Graduation thesis, Univerity of Southhampton, Southhampton, 2007.

[26] Forssén, C. Partial discharges in cylindrical cavities at variable frequency of the applied voltage. // Licentiate Thesis in Electrical Systems, KTH Electrical Engineering, Stockholm, Sweden, 2005.

[27] Chrichton, G. C.; Karlsson, P. W.; Pedersen, A. Partial Discharges in Ellipsoidal and Spheroidal Voids. // IEE Trans. on Elec. Insul. 24, 2(1989), pp. 335-342. DOI: $10.1109 / 14.90292$

[28] Ghosh, S.; Kishore, N. K. Modelling of partial discharge inception and extinction voltages of sheet examples of solid insulating materials using an artificial neural network. // IEEE proc. Sci. Meas. Tech. 149, 2(2002), pp. 73-78.

[29] Batalović, M. Modelling of partial discharges in cavities of solid dielectric (In Bosnian: Modeliranje parcijalnih pražnjenja u šupljinama čvrstog dielektrika). // MSc Graduation thesis, University of Sarajevo, Sarajevo, BiH, 2011.

\section{Authors' addresses}

Mirza Batalović, Senior assistant, M.Sc.

Faculty of Electrical Engineering, University of Sarajevo, Zmaja od Bosne bb, 71000 Sarajevo, Bosnia and Herzegovina E-mail: bmirza_etf@yahoo.com

\section{Kemo Sokolija, Full Prof. Ph.D.}

Faculty of Electrical Engineering, University of Sarajevo Zmaja od Bosne bb, 71000 Sarajevo, Bosnia and Herzegovina E-mail: kemo.sokolija@etf.unsa.ba

\section{Mesud Hadžialić, Associate Prof. Ph.D.}

Faculty of Electrical Engineering, University of Sarajevo Zmaja od Bosne bb, 71000 Sarajevo, Bosnia and Herzegovina E-mail: mesud.hadzialic@etf.unsa.ba

\section{Nejra Batalović, Expert adviser, M.Sc}

Ministry of Security of B\&H

Trg BiH 1, 71000 Sarajevo, Bosnia and Herzegovina

E-mail: nejra.batalovic@gmail.com 